\title{
Fair Design of Plug-in Electric Vehicles Aggregator for V2G Regulation
}

\author{
José Joaquín Escudero-Garzás, Member, IEEE, Ana García-Armada, Senior Member, IEEE, and \\ Gonzalo Seco-Granados, Senior Member, IEEE
}

\begin{abstract}
Plug-in electric vehicles (PEVs) have recently attracted much attention due to their potential to reduce $\mathrm{CO}_{2}$ emissions and transportation costs and can be grouped into entities (aggregators) to provide ancillary services such as frequency regulation. In this paper, the application of aggregators to frequency regulation by making fair use of their energy storage capacity is addressed. When the power grid requires frequency regulation service to the aggregator to adjust the grid frequency, the PEVs participating in providing the service can either draw energy (as it is usually done to charge the vehicle) or deliver energy to the grid by means of the vehicle-to-grid (V2G) interface. Under the general framework of optimizing the aggregator profit, different methods, such as state-dependent allocation and the water-filling approach, are proposed to achieve a final state of charge (SOC) of the PEVs that satisfy the desired fairness criteria once the regulation service has been carried out.
\end{abstract}

Index Terms-Aggregator, fairness, frequency regulation service, plug-in electric vehicle (PEV), state of charge (SOC), vehicle to grid (V2G).

\section{INTRODUCTION}

\section{A. Motivation and Background}

$\mathbf{E}$ LECTRIC power systems are experiencing a profound change driven by the need for environmental compromise and energy conservation. To this aim, the electric power grid must be transformed into a "smart grid," where computing and communication technologies and services are integrated with the electric power infrastructure [1]. In this paradigm, plug-in electric vehicles (PEVs) are considered key actors in the new electric power framework due to their potential to reduce $\mathrm{CO}_{2}$ emissions and transportation costs [2]-[4]. The progressive deployment of PEVs predicted for the next few years leads to

Manuscript received December 8, 2011; revised April 4, 2012 and June 13, 2012; accepted July 25, 2012. Date of publication August 7, 2012; date of current version October 12, 2012. The work of J. J. Escudero-Garzás and G. Seco-Granados was supported by the Grant of Spanish Government TEC2011-28219. The work of A. García-Armada was supported by the GRE3N TEC2011-29006-C03-03 and COMONSENS CSD2008-00010 projects. The review of this paper was coordinated by Prof. M. Krishnamurthy.

J. J. Escudero-Garzás is with the Department of Telecommunications and Systems Engineering, Universitat Autònoma de Barcelona, 08193 Barcelona, Spain (e-mail: josejoaquin.escudero@uab.cat).

A. García-Armada is with the Department of Signal Theory and Communications, University Carlos III of Madrid, 28911 Madrid, Spain (e-mail: agarcia@tsc.uc3m.es).

G. Seco-Granados is with the Department of Telecommunications and Systems Engineering, Universitat Autònoma de Barcelona, 08193 Barcelona, Spain (e-mail: gonzalo.seco@uab.cat).

Color versions of one or more of the figures in this paper are available online at http://ieeexplore.ieee.org.

Digital Object Identifier 10.1109/TVT.2012.2212218 very carefully consider the implications and advantages derived from a large number of PEVs connected to the smart grid [5], [6]. As an example, the U.S. Department of Energy estimates that there will be more than 1.2 million PEVs by the end of 2015 [7].

Frequency regulation (or simply regulation) is an ancillary service that is responsible for maintaining the frequency of the grid at its nominal value $(60 \mathrm{~Hz}$ in the United States and $50 \mathrm{~Hz}$ in Europe), i.e., to control the frequency fluctuations in the grid [8]. These frequency variations are caused by supply-demand imbalances, and therefore, generation should match the load demand to compensate for the fluctuations. Among the ancillary services, regulation has the highest market value for PEVs and is profitable for both PEVs and market operators [9].

Two different regulation services can be found based on the matching between power generation and total load (see Fig. 1). Regulation-down service consists in matching generation and load when the former is larger than the latter, i.e., there is an excess of power in the grid that causes an increase in the value of the frequency. On the other hand, regulation-up service consists in matching generation and load when there exists a deficit of power that causes a decrease in the frequency (load is larger than generation). Regulation services can be provided by dispatching generation to match the load [10]-[12]: Generators can provide regulation-down or regulation-up by reducing their production or giving energy to the grid, respectively, to match the load. However, the fast-responding generators required for frequency regulation operation, such as wind power systems, photovoltaic generators, or natural gas and coal units, are usually expensive and/or have large carbon emissions. Similarly, controllable loads such as batteries and flywheels can also provide regulation-up and -down services, where regulation-up and -down are provided by turning off and on the energy storage system, respectively [13]-[15]. These regulation services are said to be unidirectional as the energy only flows from or to the grid.

Alternatively, PEVs can be proposed to perform regulation service [16]; when they are parked and plugged into the grid, they can be used as a large virtual distributed battery or generator. ${ }^{1}$ Regulation-down can be done by charging the PEV batteries from the grid, and regulation-up can be achieved by discharging the PEV batteries to the grid. This latter case permits energy to flow from the vehicle to the grid and is

\footnotetext{
${ }^{1}$ Note that, although PEVs are understood to be pure electric vehicles, plugin hybrid electric vehicles can also be used to provide frequency regulation service.
} 


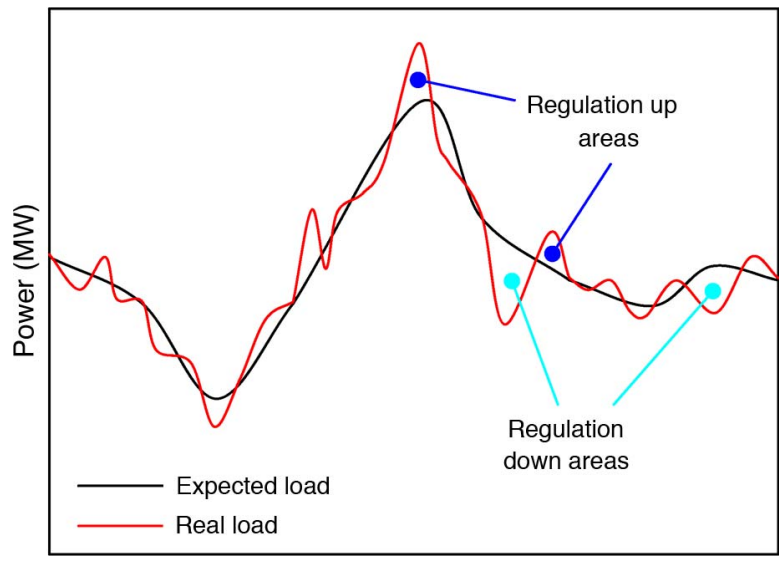

Fig. 1. Example of frequency regulation.

commonly referred to as vehicle-to-grid (V2G) operation [17]. Therefore, the regulation service offered by the PEVs is bidirectional since the energy flows from and to the grid. In the remainder of this document, the term $V 2 G$ regulation is used to denote bidirectional regulation when $\mathrm{V} 2 \mathrm{G}$ is used to perform regulation-up.

Nevertheless, although PEV owners may obtain some benefit by individually providing frequency regulation service [16], [18], [19], the use of electric vehicles (EVs) for V2G regulation only makes sense if a large number of them are jointly considered and the resulting resources (sum-power or sum of reserved energy capacity) are managed by an aggregator [20]. Aggregators (also known in the related literature as aggregation agents) are intermediate companies or computational entities that organize distributed small-scale generation/storage resources to provide large-scale services, such as regulation and capacity bidding. Therefore, aggregators play a key role between users and the independent system operator (ISO), whose relation is further explained in the next section. In the present case, aggregators manage the PEV batteries and offer frequency regulation service. Moreover, the regulation service only has a significant impact on the electrical network if it is provided and sold in the electricity market by a large fleet of PEVs and not by individual PEVs [21], given the very small energy that PEVs can provide (some kilowatt-hour), compared with the total grid demand (on the order of megawatt-hour).

However, the most relevant characteristic of an aggregator for PEVs is the mobility factor inherent to any vehicle. Mobility implies that a PEV may provide ancillary services from its very location, no matter where that location is. ${ }^{2}$ In addition, this leads us to another important challenge: Two-way communications between the aggregator and the PEV are essential to manage services provided by PEVs. Finally, another important challenge is that the aggregator has to deal with the classical energy flow from the grid and also with the recently approved interface that allows one to draw power electricity from the PEVs to the grid, i.e., the V2G interface. All these characteristics are considered in this paper, as detailed throughout the next two sections.

${ }^{2}$ Obviously, if there exists a plug and the vehicle is not moving.

\section{B. Related Work}

After the series of works of Kempton and Tomic [9], [16], [22] showing the economical value of regulation service with the participation of EV aggregator, it is only over the last few years in which this topic has attracted the interest of the research community.

Two trends are observed in the design of PEV aggregators for regulation service. The first trend is to consider that both upand down-regulation are provided by means of unidirectional regulation on the basis that a day-ahead generation schedule can be predicted. In this case, energy is delivered by the grid to the loads. As generation must match the load to keep the nominal frequency, frequency deviations are compensated by making loads controllable when generation does not follow the predicted generation schedule. This is also known as "loadonly" regulation: When the controllable loads are the PEVs, battery regulation is achieved by scheduling the periods of time when the batteries are charged around a target level of charge [23]. Han et al. presented an optimal charging strategy for frequency regulation under the control of aggregators [24], where the objective is that each PEV charges until its desired state of charge (SOC) is reached, and the regulation service is done by controlling the charging periods of the vehicles. However, they consider neither any frequency regulation signal nor the real-time power required for regulation. Sortomme and El-Sharkawi proposed an algorithm to maximize the aggregator profit while regulation is performed by varying the PEV's charging rate around its preferred operating point (POP), and the optimal POP is calculated [25]. In the same line, EVs can be considered as controllable loads to accommodate the intermittency of renewable power generators and to perform frequency regulation [26]. Pillai and Bak-Jensen proposed aggregated EVbased battery storage models representing a V2G system for frequency regulation in the Danish power system [27], [28]. However, they do not evaluate the aggregator profit, and power is evenly distributed among the PEV participants.

The second alternative is to provide $\mathrm{V} 2 \mathrm{G}$ regulation, where the PEV charges its battery for regulation-down and discharges the battery for regulation-up. In contrast with unidirectional regulation, energy flows from the grid to the PEV (regulationdown) and from the PEV to the grid (regulation-up). White and Zhang extended the model of Kempton [22] to the nonexclusive use of V2G for regulation and peak-load reduction [29]. A related work is done by Quinn et al. [30], comparing the centralized architecture (EVs directly connected to the ISO) with the aggregative architecture in terms of availability, reliability, and revenue. They conclude that, although the revenue is reduced if the aggregative architecture is used, the centralized architecture is less reliable and provides lower availability, as well as being unacceptably complex and unscalable to utilities. In [31], the conditions under which plug-in hybrid EVs can generate revenues from Sweden and Germany are investigated, although costs are not included in the analysis. In [32] and [33], Kamboj et al. discussed different strategies to form PEV coalitions, which are represented by a multiagent system, with the objective of efficiently using the PEVs for the regulation service. Dallinger et al. evaluated in [34], for the German case, the economic impact of the unpredictable mobility of the EVs 
when they provide regulation power reserves and an aggregator is not used. Wu et al. presented a game-theoretic approach that considers PEVs as players [35]. In the proposed game, PEV's participation in regulation is encouraged through pricing.

In [24], [25], and [33], in one form or another, the individual desired level of charge for the EV after regulation service is considered. Nevertheless, none of them is oriented to globally achieve a power distribution among the PEVs that can be considered fair according to a desired criterion, which is the goal of our paper.

\section{Our Contribution}

It can be discussed whether unidirectional regulation is more convenient than $\mathrm{V} 2 \mathrm{G}$ regulation. However, unidirectional regulation reduces the participation of the PEVs in regulation ${ }^{3}$ and also offers lower power levels [25]. Moreover, the frequent and small charge and discharge of the battery (shallow cycling) increases the battery lifetime in terms of the total energy delivered by the battery during its lifetime, which is also known as energy throughput [29], [36]. Therefore, although $\mathrm{V} 2 \mathrm{G}$ regulation requires some additional hardware, profits are considerably higher than those obtained with unidirectional regulation when the objective is to maximize the participants' profit; then, V2G regulation is adopted for all the schemes developed in this work.

In this paper, different criteria are investigated for the fair distribution of power for $\mathrm{V} 2 \mathrm{G}$ regulation service among the PEVs that form the aggregator based on the optimization of the aggregator profit. Two-way communications are taken into account to keep the information updated after each regulation signal. Thus, this study is focused on the resulting SOC of the PEVs after each regulation instant. It is assumed, for all the criteria under study, that the optimization problem is constrained by the fact that the SOC of each PEV's battery must be between a maximum $\left(\mathrm{SOC}_{\max }\right)$ and a minimum $\left(\mathrm{SOC}_{\min }\right)$ level. The profit obtained by PEVs is also calculated.

The contributions of this paper are, on the one hand, a general formulation of the aggregator maximization problem for $\mathrm{V} 2 \mathrm{G}$ regulation and, on the other hand, the schemes that implement the different criteria to achieve different degrees of fairness among the PEVs. More specifically, the following issues are developed:

1) state-dependent utility scheme that proportionally allocates power to the PEVs according to their available battery;

2) water-filling algorithm for $V 2 G$ regulation, which departs from the charging dynamics approach (see Section V) and exploits the similarities between the power distribution problem for $\mathrm{V} 2 \mathrm{G}$ regulation and the power allocation problem for parallel channels in communications;

3) variance minimization scheme that minimizes the SOC variance with respect to the mean SOC average of the participating PEVs.

These schemes, together with the even power distribution, are compared through the fairness index (FI), which is defined in Section IX: the results section.

\footnotetext{
${ }^{3}$ For example, if an EV has its maximum level of charge, it cannot participate in regulation since it is unable to charge any additional power.
}

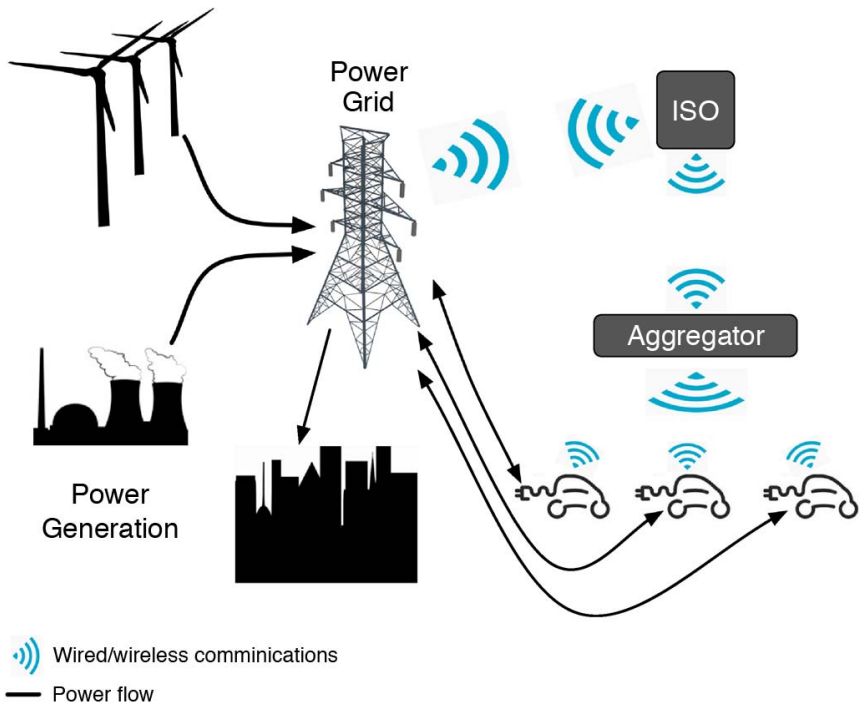

Fig. 2. Power system model.

The remainder of this work is organized as follows: In Section II, the system model is presented, which includes power system, frequency regulation market, revenue, and cost models. In Section III, the general problem of aggregator profit maximization is formulated. The state-dependent utility approach is introduced in Section IV. Section V presents the charging dynamics approach, which is the base for the development of the water-filling algorithm detailed in Section VI. The FI is presented in Section VII, where the problem is formulated in terms of the FI. The variance minimization approach is detailed in Section VIII. Results are presented in Section IX, and finally, conclusions are shown in Section X.

\section{SySTEM MODEL}

\section{A. Power System Model}

Consider the system shown in Fig. 2. The main components of the system are the power grid, ISO, aggregator, and PEVs. We assume that $N$ is the number of PEVs associated with an aggregator that is ready to provide regulation in real time during the compromised period, assuming also that $N$ is large enough (on the order of hundreds of vehicles) to provide the capacity and electricity required for frequency regulation. If frequency regulation is needed by the power grid, the ISO requests V2G regulation to the aggregators and determines the market price for frequency regulation based on the bids submitted by the aggregators. Two-way wired or wireless communications are established to communicate the aggregators, ISO, power grid, and PEVs among them according to its representation in Fig. 2.

Let us define $P_{C}^{n}(l)$ as the capacity power of EV $n$ for regulation-up and -down (in kilowatts) at $l$ and $P^{n}(l)$ as the electricity power of EV $n$ for regulation-up and -down (in kilowatts) at $l$. For the sake of simplicity, power variables are always positive for all $n=1, \ldots, N: P^{n}(l) \geqslant 0$ and $P_{C}^{n}(l) \geqslant 0$. In the model, $P_{C}^{n}(l)$ and $P^{n}(l)$ are the variables of the optimization problem, whereas the approaches mentioned in Section I-B consider only the electricity power or the total capacity power. The reason to consider capacity power distribution among the $\mathrm{PEVs}$ at each regulation instant $l$ is that it influences the SOC at 
TABLE I

LIST OF MAIN SYMBOLS

\begin{tabular}{|ll|}
\hline$\alpha_{u}^{n}, \alpha_{d}^{n}$ & fairness parameters of $\mathrm{EV} n$ for regulation up and down \\
$c^{n}$ & V2G cost for vehicle $n$ \\
$c_{d}$ & degradation cost \\
$l$ & regulation instant (discrete) \\
$P_{C}^{T}(l)$ & total capacity power for regulation up and down $(\mathrm{kW})$ at $l$ \\
$P^{T}(l)$ & total power for regulation up and down $(\mathrm{kW})$ at $l$ \\
$P_{C}^{n}(l)$ & capacity power of $\mathrm{EV} n$ for regulation up and down $(\mathrm{kW})$ at $l$ \\
$P^{n}(l)$ & electricity power of $\mathrm{EV} n$ for regulation up and down $(\mathrm{kW})$ at $l$ \\
$p_{c}$ & capacity price $(€ / \mathrm{kW}-\mathrm{h})$ \\
$p_{e l}$ & market electricity price $(€ / \mathrm{kWh})$ \\
$r^{n}$ & revenue of vehicle $n$ \\
$\mathrm{SOC}^{n}(l)$ & state-of-charge of $\mathrm{EV} n(\mathrm{~kW})$ at $l$ \\
$\mathrm{SOC}_{\max }, \mathrm{SOC}_{\min }$ & maximum and minimum state-of-charge $(\mathrm{kW})$ \\
$U(l)$ & aggregator's profit at $l$ \\
$u^{n}(l)$ & utility of PEV $n$ at $l$ \\
$x$ & signal for regulation \\
\hline
\end{tabular}

each instant, as shown in Section III. It also affects the PEV profit since each EV is paid for its reserved capacity, and it can even sign a different contract with the aggregator, which may depend, for instance, on the size of the battery or a desired number of services per hour/day/month.

V2G regulation is requested by the ISO at instants spaced $L$ seconds apart, and our proposed schemes provide possible power allocations at each of these instants $l$. That is, if the V2G regulation service is required every $L=4 \mathrm{~s}$ during $1 \mathrm{~h}$, then the allocation problem, under any of the provided criteria, is solved $3600 / 4=900$ times (see Table I).

\section{B. Frequency Regulation Market Model}

The ancillary service market price structure is followed throughout this paper [16], where the price has two components: 1 ) a capacity price (paid for having power available for a specific service for up- or down-regulation) denoted as $p_{C}$ and 2 ) an electricity price (paid for the power actually delivered in real time for up- or down-regulation) denoted as $p_{\mathrm{el}}$. Capacity price $p_{C}$ is paid to have reserved available power, whereas electricity price $p_{\mathrm{el}}$ is paid only when power is actually used. Both prices are fixed by the ISO in two independent auctions, where $p_{C}$ is kept constant usually for a period of $1 \mathrm{~h}$, and $p_{\mathrm{el}}$ is updated at each instant $l$. These prices are valid for both upand down-regulation. The scheme of this frequency regulation market is shown in Fig. 3.

The aggregator modulates the charging/discharging process of each PEV according to its capacity and current SOC $\operatorname{SOC}^{n}(l)$, following the regulation signal $x$ that the aggregator receives from the ISO. Note that $x$ may be either directly sent by the ISO or straightforwardly generated by the aggregator from the regulation service direction (up or down). The regulation signal $x$ takes value 1 for regulation-up and takes value -1 for regulation-down, i.e.,

$$
x= \begin{cases}-1, & \text { regulation-up } \\ 1, & \text { regulation-down. }\end{cases}
$$

Once the aggregator has submitted its power bid $P_{C}^{\text {bid }}$ (for regulation-up or -down) for the next hour, if the bid is accepted

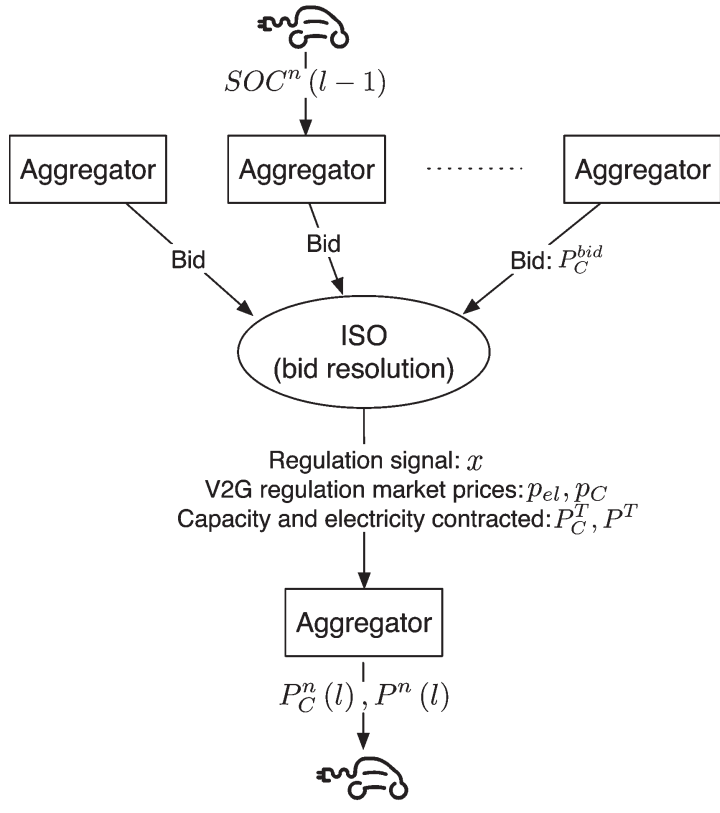

Fig. 3. Framework of the frequency regulation market and information flow for regulation service at instant $l$.

by the ISO, then price $p_{c}$ is stated, and $P_{C}^{\text {bid }}$ is evenly distributed during the next hour. For instance, if $L=15 \mathrm{~min}$ and $P_{C}^{\text {bid }}=$ $10 \mathrm{MW}$-h, at each instant $l$, we have $P_{C}^{T}(l)=2.5 \mathrm{MW}$. Next, four actions take place at each regulation instant $l$ during the following hour.

1) The capacity power $P_{C}^{n}(l)$ for each PEV is calculated by the aggregator and reserved according to the required $P_{C}^{T}(l)$. The value of the signal regulation $x$ indicates whether regulation-up or -down is required.

2) The ISO communicates to the aggregator the power requirement $P^{T}(l)$ at instant $l$, and the $\mathrm{V} 2 \mathrm{G}$ regulation power $P^{n}(l)$ is calculated by the aggregator according to the power $P^{T}(l)$.

3) The aggregator communicates to each PEV $n$ the power $P^{n}(l)$ to be exchanged with the grid, according to $x$.

4) Finally, each PEV draws/delivers $P^{n}(l)$ from/to the grid. 
The time between consecutive instants can vary from $L=4 \mathrm{~s}$ to $L=15 \mathrm{~min}$ [37], and usually, the time between consecutive regulation instants is kept constant during the period for which the capacity reserve has been required, which is commonly $1 \mathrm{~h}$.

\section{Revenue of the PEVs}

There exist different revenue schemes in the related literature for regulation-up and regulation-down. It may be assumed that, for regulation-down, a PEV only obtains revenue from the capacity service as it receives energy (see, for instance, [30]). Another possibility is to consider that, although the PEV receives energy while providing regulation-down, it provides a service that must be paid by allowing to be transferred some energy (e.g., [29] and [38]). The latter is adopted in this work, also considering a unique price $p_{\mathrm{el}}$ for both regulation-up and regulation-down. Since there exist two sources of revenue, i.e., capacity price and electricity price, the revenue for each PEV $n$ is defined accordingly as

$$
r^{n}=p_{c} P_{c}^{n}(l)+p_{\mathrm{el}} P^{n}(l) .
$$

\section{Cost Model}

The cost to produce $\mathrm{V} 2 \mathrm{G}$ regulation-up or -down is the cost associated to each kilowatt times the number of kilowatt required to a certain $\mathrm{PEV} n$, i.e., $P^{n}$. The cost to produce regulation-down is assumed to be zero because regulation-down is equivalent to charging the vehicle. The total cost in U.S. dollars per kilowatt-hour for bidirectional frequency regulation provided by PEV $n$ is denoted by $c^{n}$ and calculated as [9]

$$
c^{n}=\frac{c_{\mathrm{el}}}{\eta_{\mathrm{conv}}}+c_{d}
$$

where $c_{\mathrm{el}}$ is the cost per purchased power in U.S. dollars per kilowatt-hour, $\eta_{\text {conv }}$ is the efficiency of the vehicle's conversion of electricity through batteries back to electricity, and $c_{d}$ represents the cost of battery degradation due to extra use for $\mathrm{V} 2 \mathrm{G}$ regulation in U.S. dollars per kilowatt-hour. While $c_{\mathrm{el}}$ is simply equal to the electricity price $p_{\mathrm{el}}$, the calculation of the degradation $\operatorname{cost} c_{d}$ involves more details, as we will show next.

The degradation cost $c_{d}$ can be estimated, for deep cycling of the battery (typically around $90 \%$ ), as [9]

$$
c_{d}=\frac{c_{b}+c_{l}}{L_{c} E \mathrm{DOD}}
$$

where $c_{b}$ is the total cost of the battery in U.S. dollars, $c_{l}$ is the labor cost of battery replacement in U.S. dollars, $L_{c}$ is the battery lifetime for a certain depth of discharge (in number of cycles), $E$ is the battery capacity (in kilowatt-hour), and DOD is the depth of discharge with respect to the current state of charge SOC $^{n}$ for which $L_{c}$ was determined.

However, for $\mathrm{V} 2 \mathrm{G}$ regulation, the battery experiences repeated charging and discharging in fast succession, which can be viewed as shallow cycling (typically around 3\%). In this case, a scaling factor can be used for the shallow depths of discharge associated with $\mathrm{V} 2 \mathrm{G}$ regulation [9], [29], [30]. To be consistent with these previous works, a scaling factor of three is used, and the degradation cost for $\mathrm{V} 2 \mathrm{G}$ regulation can then be expressed as

$$
c_{d}=\frac{1}{3} \cdot \frac{c_{b}+c_{l}}{L_{c} E \mathrm{DOD}}
$$

where the values of $L_{c}, E$, and DOD are those used to calculate the degradation cost for deep cycling in (4). This means that the battery degradation cost for $\mathrm{V} 2 \mathrm{G}$ regulation is one third of the cost when compared to deep cycling.

\section{Aggregator Profit Maximization: General Problem Formulation}

Our objective in this work is to investigate different strategies to allocate power among the PEVs forming part of an aggregator for frequency regulation service and, at the same time, to achieve the SOCs of the PEVs globally meeting a given fairness criterion (e.g., minimum variance from the average value or proportional fairness). These strategies are implemented through the optimization of the aggregator profit.

In this section, the general problem of maximizing the total profit obtained by the aggregator is formulated, where the total profit is defined as the sum of the PEV profits. Taking into account the associated cost from Section II-D, the utility (profit) function of PEV $n$ is expressed as $u^{n}(l)=r^{n}-c^{n}$ for both regulation-up and -down

$u^{n}(l)= \begin{cases}p_{c} P_{C}^{n}(l)+\left(p_{\mathrm{el}}-\left(\frac{p_{\mathrm{el}}}{\eta_{\mathrm{conv}}}+c_{d}\right)\right) P^{n}(l), & \text { reg. up } \\ p_{c} P_{C}^{n}(l)+p_{\mathrm{el}} P^{n}(l), & \text { reg. down }\end{cases}$

and the resulting total aggregator profit $U(l)$ is

$$
U(l)=\sum_{n=1}^{N} u^{n}(l)
$$

We recall that, as stated in Section II-D, the cost for regulationdown is 0 , given that regulation-down is the same as charging the vehicle; thus, it is "free charging" when the EV provides regulation-down [9].

The time dependence with $l$ can be removed from the variables to alleviate the notation once it is established that the problem is solved at each instant $l$. Hence, the problem is formulated at any arbitrary instant as

$$
\begin{array}{rl}
\max _{P_{C}^{n}, P^{n}} & U=\sum_{n=1}^{N} u^{n} \\
\text { s.t. } & \sum_{n=1}^{N} P_{C}^{n}=P_{C}^{T} \\
& \sum_{n=1}^{N} P^{n}=P^{T} \\
& \operatorname{SOC}_{\max }^{n} \geqslant \mathrm{SOC}^{n}+x \nu^{n} P^{n}, \quad n=1, \ldots, N \\
& \operatorname{SOC}^{n}+x \nu^{n} P^{n} \geqslant \operatorname{SOC}_{\min }^{n}, \quad n=1, \ldots, N \\
& \operatorname{SOC}_{\max }^{n} \geqslant \mathrm{SOC}^{n}+x \nu^{n} P_{C}^{n}, \quad n=1, \ldots, N \\
& \operatorname{SOC}^{n}+x \nu^{n} P_{C}^{n} \geqslant \mathrm{SOC}_{\min }^{n}, \quad n=1, \ldots, N \\
& P^{n} \geqslant 0, P_{C}^{n} \geqslant 0, \quad n=1, \ldots, N
\end{array}
$$


where $\nu^{n}$ is the charging efficiency of PEV $n$, (9) reflects the total power capacity constraint for regulation-up and -down, (10) indicates the total submitted electricity constraint for regulation-up and -down, and (11)-(14) show the maximum/ minimum achievable SOC constraints for the electricity and capacity power. Note that $\mathrm{SOC}^{n}, \mathrm{SOC}_{\max }^{n}$, and $\mathrm{SOC}_{\min }^{n}$ are expressed as power levels (in kilowatts), considering that the power is delivered during a period of time equal to the duration of an interval $l$. This problem is a linear problem (and, hence, convex) and can be optimally solved by standard optimization methods.

\section{PRofit Optimization With STATE-DEPENDENT UTILITY}

The general problem formulation presented in Section III does not contemplate fair power allocation among the PEVs. This means that the PEVs with a low SOC might provide large power for regulation-up and reach the minimum level, which is not desirable. Analogously, PEVs with high SOC might be charged with large power for regulation-down service and reach the maximum level. Both undesired situations can be avoided by relating the power contribution to the SOC, and therefore, the following weighting factors are introduced:

$$
\begin{aligned}
& \alpha_{\mathrm{up}}^{n} \triangleq \frac{\mathrm{SOC}^{n}(l)-\mathrm{SOC}_{\min }}{\mathrm{SOC}_{\text {max }}-\mathrm{SOC}_{\text {min }}} \\
& \alpha_{d}^{n} \triangleq \frac{\operatorname{SOC}_{\text {max }}-\operatorname{SOC}^{n}(l)}{\mathrm{SOC}_{\text {max }}-\mathrm{SOC}_{\text {min }}} .
\end{aligned}
$$

Let us consider first the case of regulation-up. It can be observed from (16) that, if a battery is at its lowest level, i.e., $\operatorname{SOC}^{n}(l)=$ $\mathrm{SOC}_{\min }$, then $\alpha_{\mathrm{up}}^{n}=0$. On the other hand, if a battery is at its highest level, i.e., $\operatorname{SOC}^{n}(l)=\mathrm{SOC}_{\max }$, then $\alpha_{\mathrm{up}}^{n}=1$. Thus, the utility function (6) can be modified for regulation-up such that the utility $u_{n}(l)$ is 0 if the battery level is minimum, and $u_{n}(l)$ rises as the $\operatorname{SOC}^{n}(l)$ rises up to the maximum weighted contributions $P^{n}(l)$ and $P_{C}^{n}(l)$, for $\alpha_{\mathrm{up}}^{n}=1$. Again, as it is done in the precedent section, the time dependence with $l$ is removed since the problem is solved at each instant $l$. Then, for regulation-up, the utility function is

$$
u_{\mathrm{up}}^{n}=\alpha_{\mathrm{up}}^{n}\left(p_{c} P_{C}^{n}+\left(p_{\mathrm{el}}-c^{n}\right) P^{n}\right) .
$$

The same reasoning can be done for regulation-down. In this case, $\alpha_{d}^{n} P^{n}$ and $\alpha_{d}^{n} P_{C}^{n}$ are the power contributions to $u_{n}$, with the contribution being maximum if $\mathrm{SOC}^{n}=\mathrm{SOC}_{\min }$ and 0 if $\mathrm{SOC}^{n}=\mathrm{SOC}_{\max }$. In this case, the resulting expression is

$$
u_{d}^{n}=\alpha_{d}^{n}\left(p_{c} P_{C}^{n}+p_{\mathrm{el}} P^{n}\right) .
$$

Equations (18) and (19) can be written in a more compact way as

$$
u_{\mathrm{SD}}^{n}= \begin{cases}\alpha_{\mathrm{up}}^{n}\left(p_{c} P_{C}^{n}+\left(p_{\mathrm{el}}-c^{n}\right) P^{n}\right), & \text { if } x=-1 \\ \alpha_{d}^{n}\left(p_{c} P_{C}^{n}+p_{\mathrm{el}} P^{n}\right), & \text { if } x=1\end{cases}
$$

and similarly

$$
\alpha^{n}= \begin{cases}\alpha_{\mathrm{up}}^{n}, & \text { if } x=-1 \\ \alpha_{d}^{n}, & \text { if } x=1\end{cases}
$$

By replacing $u^{n}$ by $u_{\mathrm{SD}}^{n}$ and $P_{C}^{n}$ and $P^{n}$ by $\alpha^{n} P_{C}^{n}$ and $\alpha^{n} P^{n}$, respectively, in the general problem (8)-(15), we obtain the aggregator's profit maximization problem with state-dependent utility

$$
\begin{array}{rl}
\max _{P_{C}^{n}, P^{n}} & U=\sum_{n=1}^{N} u_{\mathrm{SD}}^{n} \\
\text { s.t. } & \sum_{n=1}^{N} P_{C}^{n}=P_{C}^{T} \\
& \sum_{n=1}^{N} P^{n}=P^{T} \\
& \operatorname{SOC}_{\max }^{n} \geqslant \mathrm{SOC}^{n}+x \nu^{n} P^{n}, \quad n=1, \ldots, N \\
& \operatorname{SOC}^{n}+x \nu^{n} P^{n} \geqslant \mathrm{SOC}_{\min }^{n}, \quad n=1, \ldots, N \\
& \operatorname{SOC}_{\max }^{n} \geqslant \mathrm{SOC}^{n}+x \nu^{n} P_{C}^{n}, \quad n=1, \ldots, N \\
& \operatorname{SOC}^{n}+x \nu^{n} P_{C}^{n} \geqslant \operatorname{SOC}_{\min }^{n}, \quad n=1, \ldots, N \\
& P^{n} \geqslant 0, P_{C}^{n} \geqslant 0, \quad n=1, \ldots, N .
\end{array}
$$

The solution to this problem provides a power allocation with a certain degree of fairness in the distribution of the total profit among the PEVs to the extent that power is proportionally allocated according to the previous SOC of the PEV.

\section{Optimization CONSIDERING CHARgING DYNAMICS}

The scheme of Section IV is useful in assigning power according to the SOC of the PEVs. However, as it was previously mentioned, proportional fair power allocation is also of interest in this study. With this objective in mind, this and the following section are developed.

Let us now consider the criterion of maximizing the difference between the SOC of the PEV $n$ at the present time $l$, which is represented by $\operatorname{SOC}^{n}(l)$, and the SOC of that PEV at the previous regulation instant, which is represented by $\operatorname{SOC}^{n}(l-1)$, since the higher this difference is, the higher the amount of required energy, and the higher the profit for user $n$. The charging dynamics can be described by the following equation:

$$
\operatorname{SOC}^{n}(l)=\operatorname{SOC}^{n}(l-1)+x(l) \nu^{n} P^{n}(l)
$$

where $x(l)$ is the regulation signal.

In this case, the optimization problem is formulated in terms of the capacity power $P_{C}^{n}(l)$, instead of both $P_{C}^{n}(l)$ and electricity power $P^{n}(l)$, given that the latter can be obtained from the former, as will be shown later in this section. Indeed, $P^{n}(l)$ is usually as large as about $10 \%$ of the capacity $P_{C}^{n}(l)$ [9]; thus, the problem is solved in $P_{C}^{n}(l)$, and after that, capacity power is proportionally allocated to each PEV $n$ with respect to the calculated $P^{n}(l)$. Thus, more conservative constraints are applied to this problem since $\mathrm{SOC}_{\max }^{n} \leqslant \mathrm{SOC}^{n}(l)+P_{C}^{n}(l)$ is used instead of $\mathrm{SOC}_{\max }^{n} \leqslant \mathrm{SOC}^{n}(l)+P^{n}(l)$. Equivalent consideration is taken for the $\mathrm{SOC}_{\min }^{n}$ constraint. Nevertheless, $\mathrm{SOC}^{n}(l)$ is updated with $P^{n}$ once the problem has been solved at instant $l$, as given by (30). 
If the problem is formulated the other way around, i.e., in terms of $P^{n}(l)$ and calculating $P_{C}^{n}(l)$ afterward, a result that violates the maximum SOC constraint, i.e., $\mathrm{SOC}_{\max }^{n} \leqslant$ $\operatorname{SOC}^{n}(l)+P_{C}^{n}(l)$, may be obtained by proceeding in such manner since $P_{C}^{n}(l)$ is usually several times larger than $P^{n}(l)$.

Note that $x \in\{-1,1\}$, and therefore, the difference $\operatorname{SOC}^{n}(l)-\operatorname{SOC}^{n}(l-1)$ can be positive or negative. Then, the optimization problem is expressed as

$$
\begin{aligned}
\max _{P_{C}^{n}(l)} & \sum_{n=1}^{N}\left|\operatorname{SOC}^{n}(l)-\operatorname{SOC}^{n}(l-1)\right|=\sum_{n=1}^{N} \nu^{n} P_{C}^{n}(l) \\
\text { s.t. } & \sum_{n=1}^{N} P_{C}^{n}(l)=P_{C}^{T} \\
& \quad \operatorname{SOC}_{\text {max }}^{n} \geqslant \operatorname{SOC}^{n}(l)+x(l) \nu^{n} P_{C}^{n}(l), \quad n=1, \ldots, N
\end{aligned}
$$

$$
\operatorname{SOC}^{n}(l)+x(l) \nu^{n} P_{C}^{n}(l) \geqslant \operatorname{SOC}_{\text {min }}^{n}, \quad n=1, \ldots, N
$$

$$
P_{C}^{n} \geqslant 0, \quad n=1, \ldots, N
$$

which is a linear problem. Then, $P^{n}(l)$ is now calculated as

$$
P^{n}(l)=k P_{C}^{n}(l)
$$

where $k=\left(P^{T} / P_{C}^{T}\right) \leqslant 1$ is a constant that scales the electricity power to the required capacity power and that allows calculating the individual $P^{n}(l)$ from $P_{C}^{n}(l)$, as both values $P_{T}$ and $P_{C}^{T}$ are given by the ISO to the aggregator through signaling. Once the total power assignment is obtained, the aggregator profit at $l$ is calculated as

$$
U(l)=\sum_{n=1}^{N} u^{n} .
$$

This approach is also the starting point in developing an algorithm based on communications concepts that achieves proportional fairness, as detailed in the next section.

\section{WATER-FILLING APPROACH}

Now, let us consider the case of frequency regulation-down for the sake of developing the fundamental aspects of the waterfilling approach, which are extended to regulation-up later in this section. The charging dynamics (30) can be rewritten as

$$
u_{\mathrm{ch}}^{n}=\frac{\operatorname{SOC}^{n}(l)}{\operatorname{SOC}^{n}(l-1)}=1+\nu^{n} \frac{P^{n}(l)}{\operatorname{SOC}^{n}(l-1)}
$$

which expresses the ratio of the new $\operatorname{SOC}^{n}(l)$ with respect to the previous one $\operatorname{SOC}^{n}(l-1)$. Then, by maximizing (38), the power for regulation of PEV $n$ is maximized, and consequently, the aggregator profit is also maximized.
However, the maximization of $\sum_{n=1}^{N} u_{\mathrm{ch}}^{n}$ may lead to unfair allocation of $P^{n}$. A widely adopted solution is the use of the logarithmic function, which is concave, and therefore, the resulting solution has the property of proportional fairness in $P^{n}(l)$ [39]. Thus, if the design criterion for the aggregator is proportional fairness, the problem can be reformulated as

$$
\begin{aligned}
\max _{P^{n}(l)} & \sum_{n=1}^{N} \log u_{\mathrm{ch}}^{n}=\sum_{n=1}^{N} \log \left(1+\nu^{n} \frac{P^{n}(l)}{\operatorname{SOC}^{n}(l-1)}\right) \\
\text { s.t. } & \sum_{n=1}^{N} P^{n}(l)=P^{T} \\
& \operatorname{SOC}_{\text {max }}^{n} \geqslant \operatorname{SOC}^{n}(l)+\nu^{n} P^{n}(l) \quad n=1, \ldots, N \\
& \operatorname{SOC}^{n}(l)+\nu^{n} P^{n}(l) \geqslant \operatorname{SOC}_{\text {min }}^{n} \quad n=1, \ldots, N \\
& P^{n}(l) \geqslant 0, \quad n=1, \ldots, N .
\end{aligned}
$$

It can be seen that there exists a great similarity between the problem of allocating power for V2G regulation to PEVs and a very well studied problem in both wireless and wireline communication systems: power allocation among parallel channels [40]. The power allocation problem is given as follows: For a given set of $N$ parallel channels, the total transmit power $P$ must be allocated among them to maximize the total transmission rate. The transmission rate per channel is equal to $\log \left(1+\left(P_{i} / N_{i}\right)\right)$, where $P_{i}$ is the power allocated to channel $i$ and $N_{i}$ is the Gaussian noise power associated with channel $i$. This problem is formulated as

$$
\begin{aligned}
\max & \sum_{i=1}^{N} \log \left(1+\frac{P_{i}}{N_{i}}\right) \\
\text { s.t. } & \sum_{i=1}^{N} P_{i} \leqslant P \\
& P_{i} \geqslant 0 \text { for all } i=1, \ldots, N .
\end{aligned}
$$

Using the Lagrangian multipliers method to solve the problem [41], the Lagrangian function to be maximized is

$$
\sum_{i=1}^{N} \log \left(1+\frac{P_{i}}{N_{i}}\right)+\mu\left(\sum_{i=1}^{N} P_{i}-P\right)
$$

and differentiating with respect to $P_{i}$

$$
\frac{1}{P_{i}+N_{i}}+\mu=0
$$

The solution to this problem is

$$
P_{i}=\left(\lambda-N_{i}\right)^{+}
$$

where $(x)^{+}=\max \{0, x\}$. The solution is graphically illustrated in Fig. 4. Vertical levels $N_{i}$ indicate the noise levels in the channels. As power level $\lambda$ is increased from zero, power $P_{i}$ is allocated to the channels with the lowest noise. In our example, the first channel to be allocated some power is Channel 2. When the available power $\lambda$ is increased still further, some of the power is distributed into noisier channels. 


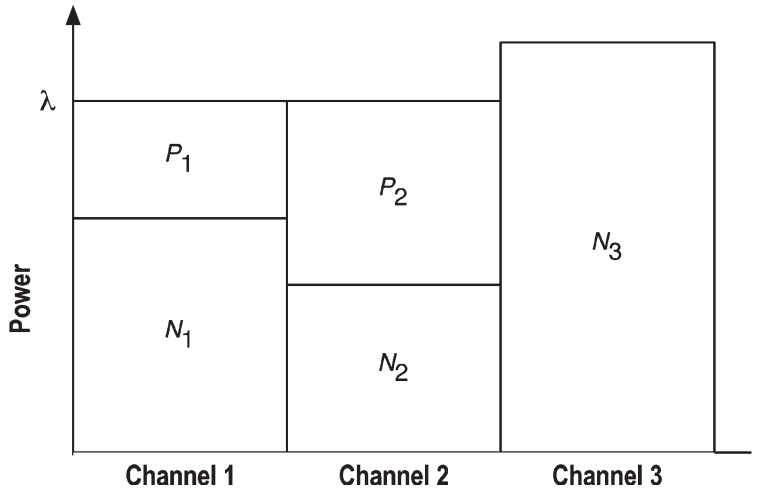

Fig. 4. Water filling for three parallel channels, where Channel 3 is unable to allocate any power.

This process is identical to the way in which water distributes itself in a container. Hence, it is commonly referred to as "water filling."

Now, the similarities between the two problems can be perceived. The parallel channels can be identified with the PEVs, the power allocated to a channel for transmission $P_{i}$ with the power drawn/charged by a PEV for frequency regulation $P^{n}$, the inverse of the power noise $\left(1 / N_{i}\right)$ with the factor $\nu^{n}\left(1 / \operatorname{SOC}^{n}(l-1)\right)$, and the total transmit power with the total power required for $\mathrm{V} 2 \mathrm{G}$ regulation. Given that water-filling algorithms have proved to be very effective in practical systems [42], they can be used for the problem of power distribution among PEVs for frequency regulation.

The following algorithm, inspired by the water-filling solution, is proposed for both regulation-up and regulation-down for power electricity assignment (see Fig. 5). Since the algorithm is solved at each instant $l$, the time dependence with $l$ is again removed for clarity. It can be distinguished between the two cases regulation-up and -down, to make the PEVs with the highest SOC first participate in regulation-up and similarly PEVs with the lowest SOC first participate in regulation-down. Therefore, the algorithm is slightly different for regulationdown $(x=1)$ and regulation-up $(x=-1)$, as explained next. If, for instance, regulation-down with an initial water level (which is denoted by $W$ ) of 0 is considered to be updated in ascending direction, the batteries with low power level (low SOC) are charged first, which is more convenient to avoid PEVs with higher SOC from exceeding the maximum level of charge $\mathrm{SOC}_{\max }$. Similarly, for regulation-up, an initial high value of water level is set (for instance, $P^{T}$ ) and is updated in descending direction. In this case, power is first extracted from the batteries with higher SOC, thus avoiding batteries with low power level to reach the minimum level of charge $\mathrm{SOC}_{\min }$.

The algorithm works as follows: Once the type of regulation according to the value of $x$ is decided, it is verified if the total available power $P^{T}$ has been distributed among the batteries $\left(\sum_{n=1}^{N} P^{n}-P^{T}>\varepsilon\right)$. If yes, the algorithm ends. If not, the algorithm updates the SOC and ends if none of the batteries can provide additional power for regulation $\left(\mathrm{SOC}_{n}<\mathrm{SOC}_{\min }\right.$ or $\left.\mathrm{SOC}_{n}>\mathrm{SOC}_{\max }\right)$. Otherwise, the water level is updated ( $W=W+\Delta$ or $W=W-\Delta$ ), and the process returns to the total available power condition. Parameters $\varepsilon \geqslant 0$ and $\Delta>0$ are set up according to the desired accuracy: The lower their values, the higher the achieved accuracy in distributing the total power among the PEVs.

This algorithm could similarly be applied to the power capacity distribution to obtain $P_{C}^{n}$.

\section{FAIRNESS INDEX MAXIMIZATION PROBLEM}

One more possibility is to use the FI definition from [43] as a measure of the fairness accomplished among the PEVs in terms of their SOCs.

For a general case, it departs from a given solution $\left\{s_{n}^{*}\right\}$ to a general problem that is assumed to be the fairest one, where the variables represent the $\mathrm{SOC}$ of each $\mathrm{PEV} \mathrm{SOC}{ }_{n}$. Now, a new solution $\left\{s_{n}\right\}$ is defined, which is a function of both the solution to be tested $\left\{s_{n}^{\prime}\right\}$ and the fairest solution $\left\{s_{n}^{*}\right\}$, that is

$$
s_{n}=\frac{s_{n}^{\prime}}{s_{n}^{*}} \text { for all } n=1, \ldots, N
$$

and the FI is defined as

$$
\mathrm{FI}=\frac{\left(\sum_{n=1}^{N} s_{i}\right)^{2}}{N \sum_{n=1}^{N} s_{i}^{2}} .
$$

The FI can also be geometrically specified, assuming that $\mathbf{s}$ is the vector of dimension $N$ composed by $\left\{s_{i}\right\}$ and that this vector is compared with the $N$ all-ones reference vector $\mathbf{e}=(1, \ldots, 1)^{T}$ using the scalar product. Therefore, (51) can be rewritten as

$$
\mathrm{FI}=\frac{\left(\mathbf{e}^{T} \mathbf{s}\right)^{2}}{S\|\mathbf{s}\|^{2}}=\frac{(\|\mathbf{s}\|\|\mathbf{e}\| \cos \theta)^{2}}{\|\mathbf{e}\|^{2}\|\mathbf{s}\|^{2}}=\cos ^{2} \theta
$$

where $\theta$ is the angle formed between vectors $\mathbf{e}$ and $\mathbf{s}$.

Note that, according to (52), the higher the value of FI, the closer the tested solution $\mathbf{s}^{\prime}$ to the fairest solution. In other words, if $\theta=0$, the fairness achieved with $\mathbf{s}^{\prime}$ is the best possible, so $\mathbf{s}^{\prime}$ is the fairest solution and $\mathrm{FI}=1$. On the contrary, if $\mathrm{FI}=0$, the solution is totally unfair.

Applied to our problem, the FI must then be maximized to achieve an assignment as fair as possible. If $\mathbf{s}_{l}$ and $\mathbf{s}_{l-1}$ represent the SOC vector at regulation instants $l$ and $l-1$, respectively, the resulting problem is

$$
\begin{gathered}
\max _{\mathbf{s}_{l}} \mathrm{FI}=\frac{\left(\mathbf{e}^{T} \mathbf{s}_{l}\right)^{2}}{S\left\|\mathbf{s}_{l}\right\|^{2}} \\
\text { s.t. } \mathbf{e}^{T}\left(\mathbf{s}_{l}-\mathbf{s}_{l-1}\right)=x P_{C}^{\text {tot }} \\
\mathbf{s}_{\min } \leqslant \mathbf{s}_{l} \\
\mathbf{s}_{l} \leqslant \mathbf{s}_{\max } .
\end{gathered}
$$

However, this problem is not convex, given that the optimization function is not concave, and therefore, the FI is used only for comparison purposes in the results section, and the problem is formulated as the variance minimization problem, as will be shown next. 


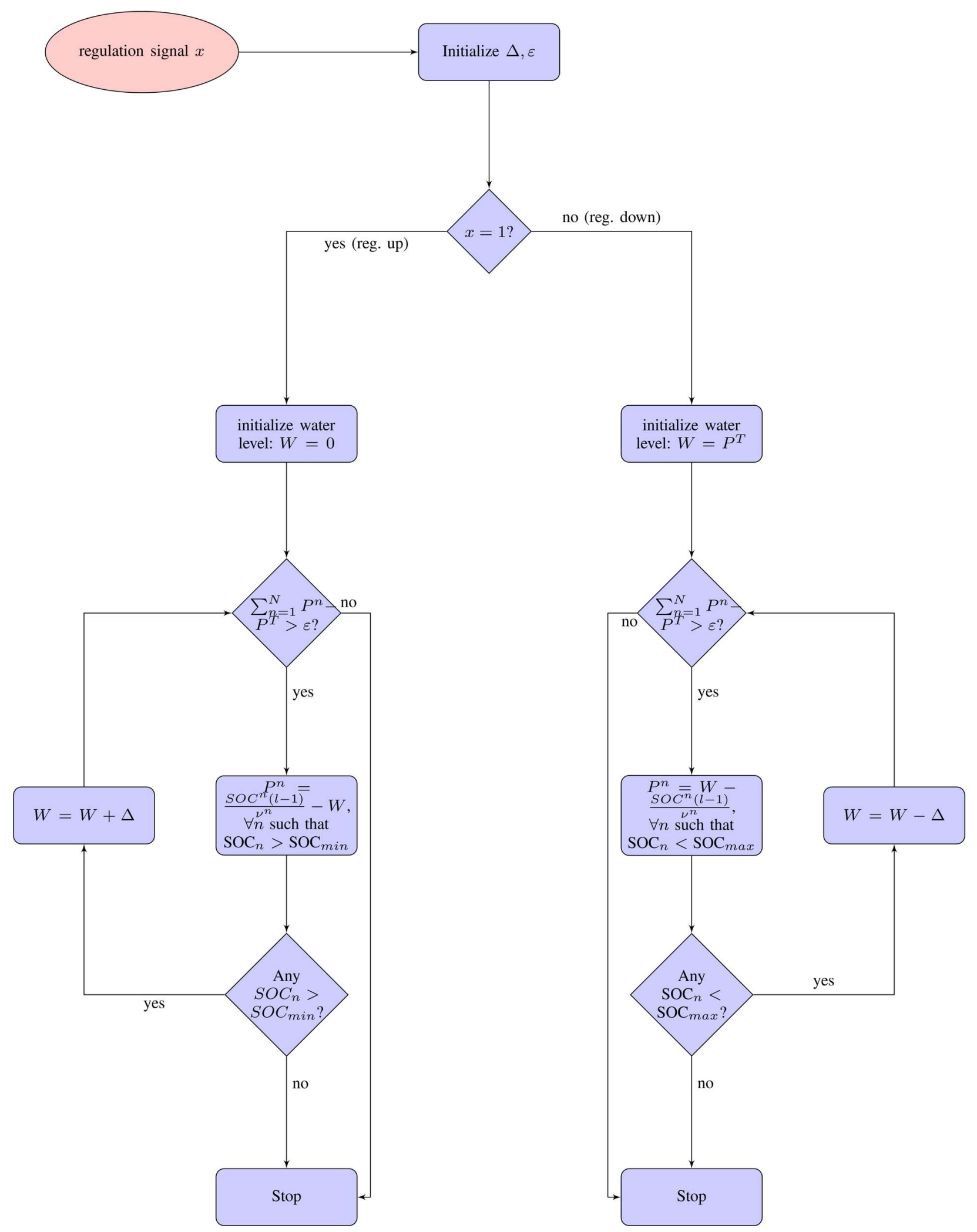

Fig. 5. Algorithm 1. Frequency regulation water filling for power electricity assignment.

VIII. VARiance Minimization Problem

In this section, the problem of power allocation to the PEVs through the variance minimization problem in vectorial notation is formulated, where the objective is to minimize the SOC sample variance, which is denoted by $\bar{\sigma}_{\mathbf{s}}^{2}$. Here, for the sake of simplicity, $s_{n}$ represents the SOC associated with PEV $n \mathrm{SOC}_{n}$, and the problem is formulated as

$$
\min \bar{\sigma}_{\mathbf{s}}^{2}=\frac{1}{N-1} \sum_{i=1}^{N}\left(s_{n}-\bar{s}\right)^{2}
$$


where $\bar{s}=(1 / N) \sum_{n=1}^{N} s_{n}=(1 / N) \mathbf{e}^{T} \mathbf{s}$ in vectorial notation $\mathbf{s}=\left(s_{1}, \ldots, s_{N}\right)^{T}$. Taking this into account, the sum term of (57) can be rewritten as

$$
\begin{aligned}
\sum_{i=1}^{N}\left(s_{n}-\bar{s}\right)^{2} & =\left(\mathbf{s}-\frac{1}{N} \mathbf{e e}^{T} \mathbf{s}\right)^{T}\left(\mathbf{s}-\frac{1}{N} \mathbf{e e}^{T} \mathbf{s}\right) \\
& =\mathbf{s}^{T}\left(\mathbf{I}-\frac{1}{N} \mathbf{e e}^{T}\right) \mathbf{s}
\end{aligned}
$$

where (59) is derived after some algebraic manipulation and realizing that $\mathbf{e}^{T} \mathbf{e}=N$. As a result, the minimization problem (57) becomes

$$
\min \bar{\sigma}_{\mathbf{s}}^{2}=\frac{1}{N-1} \mathbf{s}^{T}\left(\mathbf{I}-\frac{1}{N} \mathbf{e e}^{T}\right) \mathbf{s}
$$

where I represents the identity matrix. Recall that, if $s_{l}^{n}$ and $s_{l-1}^{n}$ represent the SOC of PEV $n$ at regulation instants $l$ and $l-1$, respectively, the charging dynamics is $s_{l}^{n}=s_{l-1}^{n}+$ $x(l) \nu^{n} P_{C}^{n}(l)$ (30). Let us also define $\mathbf{s}_{l-1}=\left(s_{l}^{1}, \ldots, s_{l}^{N}\right)^{T}$. With this notation, the standard deviation of (60) can be expressed as

$$
\begin{aligned}
\bar{\sigma}_{\mathbf{s}}^{2}=\frac{1}{N-1}\left(\mathbf{s}_{l-1}+x(l) \nu^{n}\right. & \left.\odot \mathbf{p}_{C}^{l}\right)^{T}\left(\mathbf{I}-\frac{1}{N} \mathbf{e e}^{T}\right) \\
& \times\left(\mathbf{s}_{l-1}+x(l) \nu^{n} \odot \mathbf{p}_{C}^{l}\right)
\end{aligned}
$$

where $\mathbf{p}_{C}^{l}=\left[P_{C}^{1}(l), P_{C}^{2}(l), \ldots, P_{C}^{N}(l)\right]^{T}, \nu^{n}=\left[\nu^{1}, \nu^{2}, \ldots\right.$, $\left.\nu^{N}\right]^{T}$, and $\odot$ corresponds to the component-wise vector multiplication operation. Now, the total power and SOC limit constraints must be introduced in the problem, which are equivalent to those introduced in Section III by (23) and (25), respectively. Thus, the resulting problem is

$$
\begin{aligned}
\min _{\mathbf{p}_{C}^{l}} & \bar{\sigma}_{\mathbf{s}}^{2} \\
\text { s.t. } & \mathbf{e}^{T} \mathbf{p}_{C}^{l}=P_{C}^{\text {tot }} \\
& \mathbf{s}_{\min } \leqslant \mathbf{s}_{l-1}+\nu^{n} \odot \mathbf{p}_{C}^{l} \\
& \mathbf{s}_{l-1}+\nu^{n} \odot \mathbf{p}_{C}^{l} \leqslant \mathbf{s}_{\max } \\
& \mathbf{p}_{C}^{l} \geqslant \mathbf{0}
\end{aligned}
$$

with $\bar{\sigma}_{\mathbf{s}}^{2}$ given by (61), where $\mathbf{s}_{\max }$ and $\mathbf{s}_{\min }$ are the vectors representing the maximum and minimum SOCs of each PEV, respectively.

Recall that, as in Section V, the SOC $\mathbf{s}_{l}$ is updated based on $P^{n}$ although the problem is formulated on $P_{C}^{n}$.

\section{Numerical Results}

The simulation scenario is set up as follows: The aggregator is formed by $1500 \mathrm{EVs}$ of three different types, i.e., Mini-E, Mitsubishi i-MiEV, and Tesla Roadster with battery capacities of $35 \mathrm{kWh}$ [44], $16 \mathrm{kWh}$ [45], and $53 \mathrm{kWh}$ [46], respectively. It is assumed that the presence of each type is one third of the total vehicles. It is assumed that, with respect to battery degradation, the batteries of the three types of EVs are Saft lithium-ion type and $L_{c}=1000000$-cycle lifetime at $3 \%$ [47]. While only battery EVs are used in simulations, the proposed algorithm and methods work as effectively with fleets including plug-in hybrid EVs. The initial SOC is randomly and uniformly distributed between the limit values $\mathrm{SOC}_{\max }$ and $\mathrm{SOC}_{\text {min }}$. It is assumed that each PEV electric connection is a

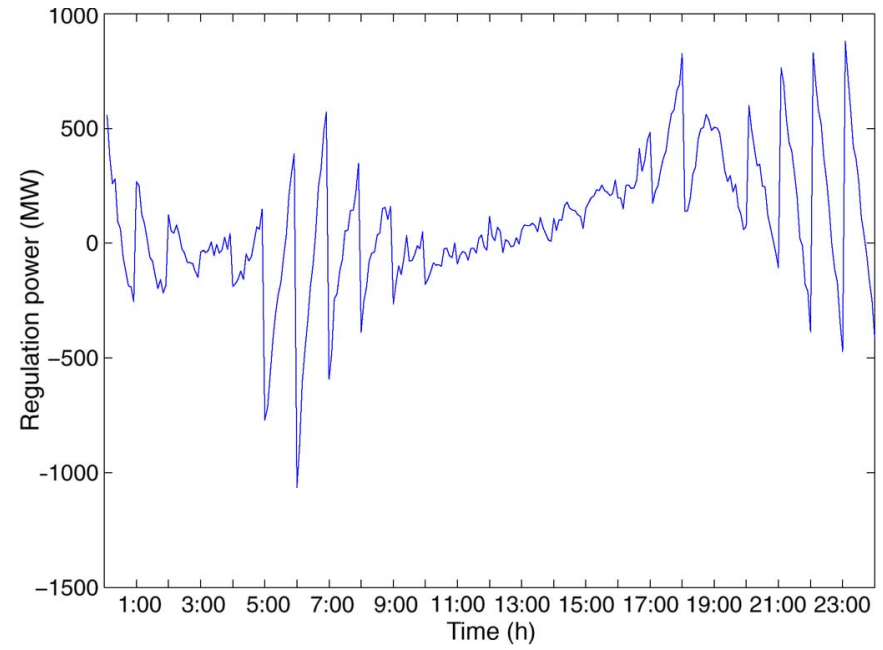

Fig. 6. Regulation power signal corresponding to March 11, 2012, from NYISO. Negative values correspond to regulation-up and positive values correspond to regulation-down.

240-V/30-A line that provides $7.2 \mathrm{kWh}$, which is sufficient for the required frequency regulation service.

For simulations, real data from the New York ISO (NYISO) are used [48]. In the NYISO market regulation is performed every $5 \mathrm{~min}$. Nevertheless, the proposed approaches are also suitable for systems where regulation is more frequently required. The regulation power signal is calculated from these data (see Fig. 6) corresponding to a complete day as the difference between the forecast load and the real time load. The capacity price is updated after $1 \mathrm{~h}$, and the regulation price is updated for every regulation interval of $5 \mathrm{~min}$. The power capacity $P_{C}^{T}$ provided by the aggregator is estimated as the $10 \%$ of the forecast demand, and the electricity power $P^{T}(l)$ is estimated to be $10 \%$ of $P_{C}^{T}$ [9]. The remaining parameter values are given in Table II. The average cumulative regulation power is represented in Fig. 7, which shows that this value is nonzero.

For comparison purposes, the results for even power distribution are also shown, which consists in distributing the required electricity power evenly among the EVs.

Fairness is first assessed through the SOC variance evolution over regulation instants shown in Fig. 8. It is observed that the water-filling algorithm converges to a null variance since its rationale is precisely to provide the same final SOC power level to the PEVs participating in the V2G regulation, irrespective of their battery capacity. The variance minimization performance is slightly worse since the problem is formulated in the variables $P_{C}^{n}$, and consequently, the constraints are also different. The performance of the other two approaches is clearly poorer, given that they are focused on maximizing the profit and not on minimizing the difference among the SOC of the EVs. Interestingly, the state-dependent utility approach exhibits a high but constant variance value because of the use of the weighting factor $\alpha^{n}$, which leads to a power assignment proportional to the relative SOC. This can be useful if an initial SOC distribution with low variance can be achieved at $0: 00$.

In Fig. 9, the fairness achieved by the proposed schemes using the FI is shown. In our case, the average-valued solution $\left\{s_{n}^{*}=\bar{s}=(1 / N) \sum_{n=1}^{N} s_{n}\right\}$ is selected, for all $n$, as the fairest 
TABLE II

SiMUlation PARAMETERS

\begin{tabular}{|c|c|c|}
\hline Cost parameter & Value & Comments \\
\hline$\eta_{\text {conv }}$ & 0.73 & Taken from [16] \\
\hline$\nu$ & 0.9 & \\
\hline$c_{l}$ & $10 \mathrm{~h} \times 30(\$ / \mathrm{h})$ & Taken from [16] \\
\hline$c_{b}$ & $580(\$ / \mathrm{kWh}) \times E_{t}(\mathrm{kWh})$ & $\begin{array}{l}\text { Industry average estimation of battery cost by } 2009 \text { is } 650(\$ / \mathrm{kWh}) \text { and it is } \\
\text { predicted a decrease of } 60 \% \text { by } 2020 \text { [49], which is considered linear. } E_{t} \text { is } \\
\text { the PEV total battery capacity }\end{array}$ \\
\hline$c_{e l}$ & $p_{e l}$ & $\begin{array}{l}\text { Hour-ahead Locational-Based Marginal Pricing (LBMP) from NYISO } \\
\text { March } 112012 \text { [48] }\end{array}$ \\
\hline DOD & $3 \%$ & Taken from [49] \\
\hline$L_{c}$ & $1,000,000$ & Taken from [49] \\
\hline$p_{c}$ & & Hour-ahead regulation pricing from NYISO - March 112012 [48] \\
\hline $\mathrm{SOC}_{\max }$ & $90 \%$ & \\
\hline $\mathrm{SOC}_{\min }$ & $10 \%$ & \\
\hline
\end{tabular}

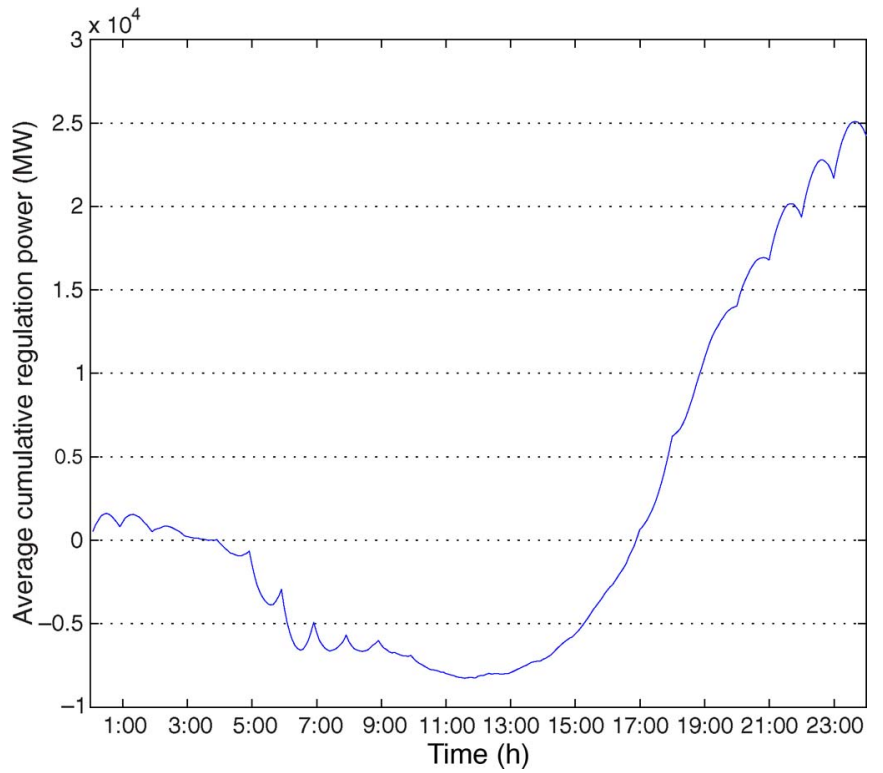

Fig. 7. Average cumulative regulation power corresponding to March 11, 2012. Negative values correspond to regulation-up and positive values correspond to regulation-down.

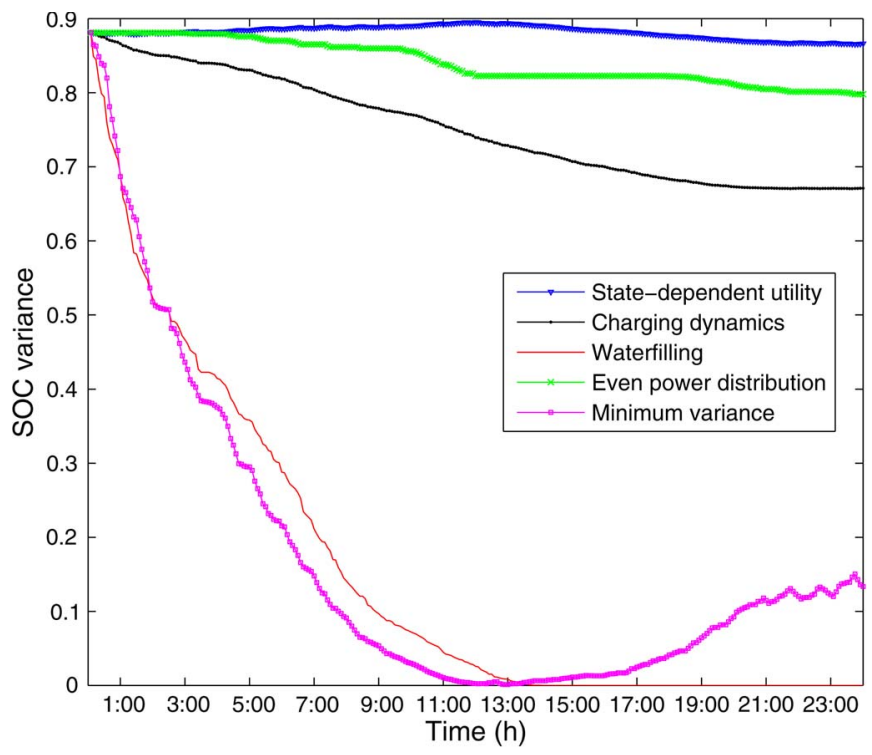

Fig. 8. SOC variance for 24-h regulation service.

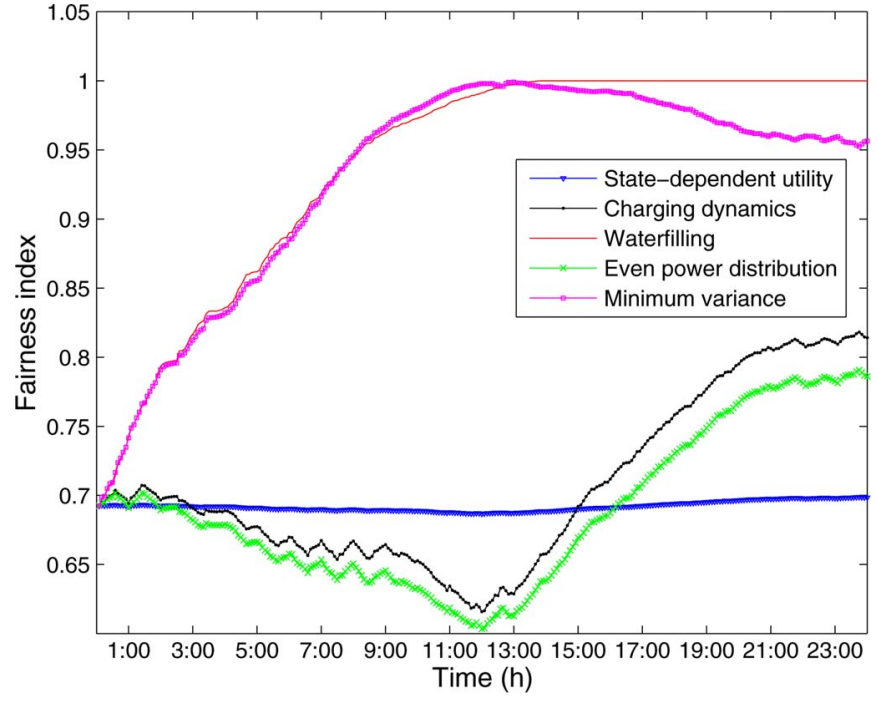

Fig. 9. FI comparison among the presented schemes for 24-h regulation service.

TABLE III

Average FI After 24-h Regulation SERvice

\begin{tabular}{|lc|}
\hline Approach & Average FI \\
\hline State-dependent utility & 0.6920 \\
Charging dynamics & 0.7064 \\
Waterfilling & 0.9406 \\
Even power distribution & 0.6880 \\
Variance minimization & 0.9299 \\
\hline
\end{tabular}

solution, where $\left\{s_{n}\right\}$ is any solution to the problem solved. The water-filling algorithm is the fairest scheme and converges to 1 at $14: 25$. This is again a consequence of the goal of the waterfilling algorithm to achieve the same SOC level for all EVs. In addition, the variance minimization approach converges to a high value, but the performance is again slightly worse due to the fact that this approach minimizes the difference between the SOC values and their average in terms of $P_{C}^{n}$. The other two approaches again provide a poorer performance since they are oriented to profit maximization. It is shown that the curve shape of the charging dynamics scheme follows the curve of even power distribution, indicating that the power is distributed in an even power fashion. 
TABLE IV

Profit Values After 24-h Regulation Service

\begin{tabular}{|lcccc|}
\hline Approach & Total profit (\$) & Profit per EV: Mean (\$) & $\begin{array}{c}\text { Maximum estimated } \\
\text { profit per EV (1 year) (\$) }\end{array}$ & Profit per EV: Variance (\$) \\
\hline State-dependent utility & 2,020 & 1.3469 & 491 & 0.1601 \\
Charging dynamics & 1,985 & 1.3233 & 483 & 1.5033 \\
Waterfilling & 1,960 & 1.3069 & 468 & 0.7512 \\
Even power distribution & 1,172 & 0.7816 & 285 & 0 \\
Variance minimization & 1,964 & 1.3092 & 478 & 0.3479 \\
\hline
\end{tabular}

The FI average values over the period of $24 \mathrm{~h}$ in Table III show the perform in average for both cases. The water-filling and variance minimization approaches exhibit quite larger values with respect to the state-dependent utility and the charging dynamics, as expected. The even power distribution approach provides a poor value in average.

Table IV shows the total profit obtained for each approach after the observed period of $24 \mathrm{~h}$. The total profit is calculated as the sum of the individual profits. The state-dependent utility obtains the highest value since the objective in this case is to maximize the sum profit $\sum_{n=1}^{N} u_{\mathrm{SD}}^{n}$. With charging dynamics, which maximizes $\sum_{n=1}^{N}\left|\operatorname{SOC}^{n}(l)-\operatorname{SOC}^{n}(l-1)\right|$, the profit is also larger than that with variance minimization. The waterfilling approach experiences a slight loss due to the quantization of the step of the algorithm with respect to variance minimization. Nevertheless, the even power distribution gives a significant lower profit due to the fact that it is not always possible to allocate the power in the vehicles without violating the SOC limit constraints. Therefore, the total power provided by the PEVs is less than the requested power; thus, the profit is lower. The maximum profit in 1 year of frequency regulation can also be estimated and can be as high as $\$ 491$ if the daily results are extrapolated to an annual forecast.

Fairness expressed in profit per PEV is also evaluated through the variance of the profit per vehicle shown in Table IV. The lowest variance is observed for state-dependent utility derived from the weighting factors $\alpha^{n}$ applied to each $\mathrm{EV}$ profit function $u_{\mathrm{SD}}^{n}$. The highest value corresponds to the charging dynamics approach since the objective is to achieve a difference $\left|\operatorname{SOC}^{n}(l)-\operatorname{SOC}^{n}(l-1)\right|$ as high as possible. With even power distribution, the variance is obviously 0 . Low variance is also observed for variance minimization in accordance with the objective of minimizing the SOC variance. An intermediate value is obtained for water filling since the objective is to achieve the same final SOC for all EVs, irrespective of their initial SOCs.

The effect of costs in the profit is evaluated for the case of state-dependent utility and shown in Fig. 10. Since the total profit obtained without costs is $\$ 2071$, the profit loss in this case due to the costs is only $2.7 \%$.

\section{Conclusion}

In this paper, a set of schemes to distribute the power for V2G regulation service when this service is provided by EVs managed by an aggregator has been presented. In contrast with the works in recent literature, the focus has been on the fair distribution of power among the EVs, instead of merely trying to optimize the aggregator profit.

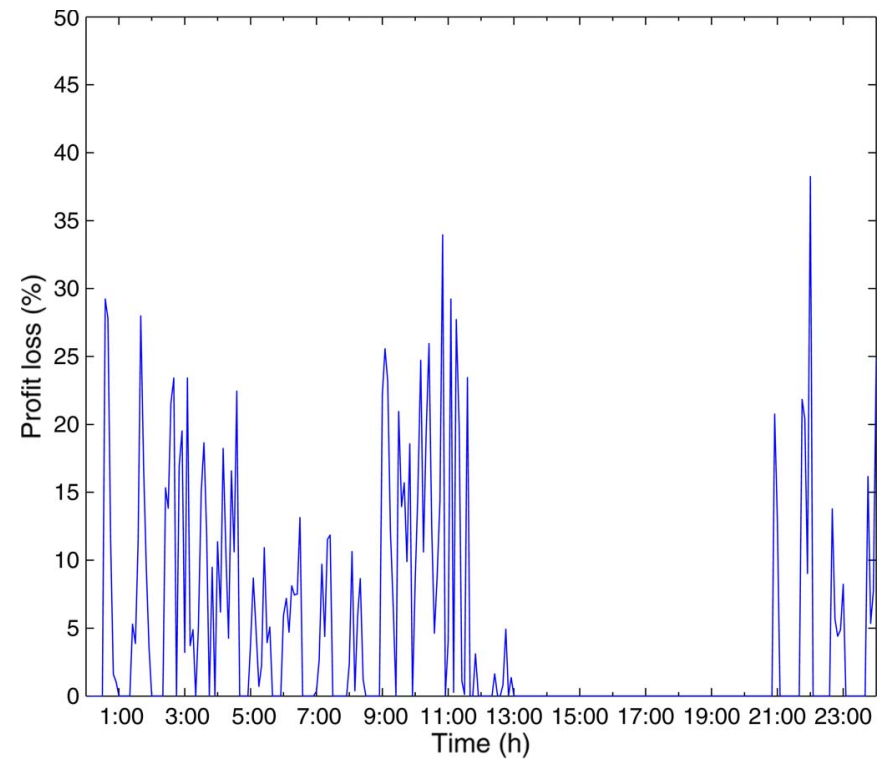

Fig. 10. Profit comparison between optimization with and without costs after 24-h regulation: state-dependent utility case.

Simulations have shown that, depending on the selected scheme, differences in the variance of the SOC of the EVs and the degree of fairness can be achieved, whereas all the schemes provide positive profit even after considering degradation costs. The water-filling approach, which was derived from an algorithm widely used in communications, can also achieve zero variance and, moreover, perfect fairness, even though water filling is not generally fair in communications. The variance minimization approach can also achieve very low variance in SOC and very good fairness in terms of FI. On the other hand, if the focus is on fair profit, the statedependent utility approach provides the fairest distribution of profit among the EVs participating in $\mathrm{V} 2 \mathrm{G}$ regulation, and the charging dynamics approach provides the highest total profit and reasonable good values of variance and fairness.

It can also be highlighted that, for any of the schemes considered, an annual maximum profit per PEV of several hundred dollars can be raised.

\section{REFERENCES}

[1] Nat. Inst. Stand. Technol., Gaithersburg, MD, NIST Framework and Roadmap for Smart Grid Interoperability Standards, Rel. 1.0, 2010. [Online]. Available: http://nist.gov/smartgrid/

[2] M. Koot, J. T. B. A. Kessels, B. de Jager, W. P. M. H. Heemels, P. P. J. van den Bosch, and M. Steinbuch, "Energy management strategies for vehicular electric power systems," IEEE Trans. Veh. Technol., vol. 54, no. 3, pp. 771-782, May 2005.

[3] B. K. Sovacool and R. F. Hirsh, "Beyond batteries: An examination of the benefits and barriers to plug-in hybrid electric vehicles (PHEVs) and a vehicle-to-grid (V2G) transition," Energy Policy, vol. 37, no. 3, pp. 1095 1103, Mar. 2009 
[4] A. G. Boulanger, A. C. Chu, S. Maxx, and D. L. Waltz, "Vehicle electrification: Status and issues," Proc. IEEE, vol. 99, no. 6, pp. 1116-1138, Jun. 2011.

[5] E. Inoa and J. Wang, "PHEV charging strategies for maximized energy saving," IEEE Trans. Veh. Technol., vol. 60, no. 7, pp. 2978-2986, Sep. 2011.

[6] R. Liu, L. Dow, and E. Liu, "A survey of PEV impacts on electric utilities," in Proc. IEEE PES ISGT, 2011, pp. 1-8.

[7] U.S. Dept. Energy, Washington, DC, One Million Electric Vehicles By 2015, 2011. [Online]. Available: http://apps1.eere.energy.gov/news/ news_detail.cfm/news_id=16717

[8] B. J. Kirby, "Frequency regulation basics and trends," U.S. Dept. Energy, Washington, DC, 2005.

[9] J. Tomic and W. Kempton, "Using fleets of electric-drive vehicles for grid support," J. Power Sources, vol. 168, no. 2, pp. 459-468, Jun. 2007.

[10] B. Tyagi and S. C. Srivastava, "A decentralized automatic generation control scheme for competitive electricity markets," IEEE Trans. Power Syst., vol. 21, no. 1, pp. 312-320, Feb. 2006.

[11] J. M. Mauricio, A. Marano, A. Gomez-Exposito, and J. L. Martinez Ramos, "Frequency regulation contribution through variable-speed wind energy conversion systems," IEEE Trans. Power Syst., vol. 24, no. 1, pp. 173-180, Feb. 2009.

[12] M. Datta, T. Senjyu, A. Yona, T. Funabashi, and C.-H. Kim, "A frequencycontrol approach by photovoltaic generator in a PV-diesel hybrid power system," IEEE Trans. Energy Convers., vol. 26, no. 2, pp. 559-571, Jun. 2011.

[13] A. Oudalov, D. Chartouni, and C. Ohler, "Optimizing a battery energy storage system for primary frequency control," IEEE Trans. Power Syst., vol. 22, no. 3, pp. 1259-1266, Aug. 2007.

[14] D. S. Callaway and I. A. Hiskens, "Achieving controllability of electric loads,” Proc. IEEE, vol. 99, no. 1, pp. 184-199, Jan. 2011.

[15] Z. Amjadi and S. S. Williamson, "Modeling, simulation, and control of an advanced luo converter for plug-in hybrid electric vehicle energy-storage system," IEEE Trans. Veh. Technol., vol. 60, no. 1, pp. 64-75, Jan. 2011.

[16] W. Kempton and J. Tomic, "Vehicle-to-grid power fundamentals: Calculating capacity and net revenue," J. Power Sources, vol. 144, no. 1, pp. 268-279, Jun. 2005.

[17] W. Kempton, J. Tomic, S. Letendre, A. Brooks, and T. Lipman, Vehicleto-grid power: Battery, hybrid, and fuel cell vehicles as resources for distributed electric power in California, Univ. California, Davis, CA. [Online]. Available: http://escholarship.org/uc/item/0qp6s4mb

[18] V. V. Viswanathan and M. Kintner-Meyer, "Second use of transportation batteries: Maximizing the value of batteries for transportation and grid services," IEEE Trans. Veh. Technol., vol. 60, no. 7, pp. 2963-2970, Sep. 2011.

[19] S. S. Raghavan and A. Khaligh, "Electrification potential factor: Energybased value proposition analysis of plug-in hybrid electric vehicles," IEEE Trans. Veh. Technol., vol. 61, no. 3, pp. 1052-1059, Mar. 2012.

[20] C. Guille and G. Gross, "A conceptual framework for the vehicle-to-grid (V2G) implementation," Energy Policy, vol. 37, no. 11, pp. 4379-4390, Nov. 2009.

[21] T. K. Kristoffersen, K. Capion, and P. Meibom, "Optimal charging of electric drive vehicles in a market environment," Appl. Energy, vol. 88, no. 5, pp. 1940-1948, May 2011.

[22] W. Kempton and J. Tomic, "Vehicle-to-grid power implementation: From stabilizing the grid to supporting large-scale renewable energy," J. Power Sources, vol. 144, no. 1, pp. 280-294, Jun. 2005.

[23] A. Brooks, E. Lu, D. Reicher, C. Spirakis, and B. Weihl, "Demand dispatch," IEEE Power Energy Mag., vol. 8, no. 3, pp. 20-29, May/Jun. 2010.

[24] S. Han, S. Han, and K. Sezaki, "Development of an optimal vehicle-togrid aggregator for frequency regulation," IEEE Trans. Smart Grid, vol. 1, no. 1, pp. 65-72, Jun. 2010.

[25] E. Sortomme and M. A. El-Sharkawi, "Optimal charging strategies for unidirectional vehicle-to-grid," IEEE Trans. Smart Grid, vol. 2, no. 1, pp. 131-138, Mar. 2011

[26] C. Ahn, C.-T. Li, and H. Peng, "Optimal decentralized charging control algorithm for electrified vehicles connected to smart grid," J. Power Sources, vol. 196, no. 23, pp. 10369-10379, Dec. 2011.

[27] J. R. Pillai and B. Bak-Jensen, "Integration of vehicle-to-grid in the Western Danish power system," IEEE Trans. Sustainable Energy, vol. 2, no. 1, pp. 12-19, Jan. 2011.

[28] J. R. Pillai and B. Bak-Jensen, "Vehicle-to-grid systems for frequency regulation in an islanded Danish distribution network," in Proc. IEEE VPPC, Sep. 2010, pp. 1-6.

[29] C. D. White and K. M. Zhang, "Using vehicle-to-grid technology for frequency regulation and peak-load reduction," J. Power Sources, vol. 196, no. 8, pp. 3972-3980, Apr. 2011.

[30] C. Quinn, D. Zimmerle, and T. H. Bradley, "The effect of communication architecture on the availability, reliability, and economics of plug- in hybrid electric vehicle-to-grid ancillary services," J. Power Sources, vol. 195 , no. 5, pp. 1500-1509, Mar. 2010.

[31] S. L. Andersson, A. K. Elofsson, M. D. Galus, L. Göransson, S. Karlsson, F. Johnsson, and G. Andersson, "Plug-in hybrid electric vehicles as regulating power providers: Case studies of Sweden and Germany," Energy Policy, vol. 38, no. 6, pp. 2751-2762, Jun. 2010.

[32] S. Kamboj, K. Decker, K. Trnka, N. Pearre, C. Kern, and W. Kempton, "Exploring the formation of electric vehicle coalitions for vehicle-to-grid power regulation," in Proc. AAMAS Workshop ATES, 2010, pp. 1-8.

[33] S. Kamboj, W. Kempton, and K. S. Decker, "Deploying power gridintegrated electric vehicles as a multi-agent system," in Proc. Int. Conf. AAMAS, 2011, pp. 13-20.

[34] D. Dallinger, D. Krampe, and M. Wietschel, "Vehicle-to-grid regulation reserves based on a dynamic simulation of mobility behavior," IEEE Trans. Smart Grid, vol. 2, no. 2, pp. 302-313, Jun. 2011.

[35] C. Wu, H. Mohsenian-Rad, and J. Huang, "Vehicle-to-aggregator interaction game," IEEE Trans. Smart Grid, vol. 3, no. 1, pp. 434-442, Mar. 2012.

[36] S. B. Peterson, J. Apt, and J. F. Whitacre, "Lithium-ion battery cell degradation resulting from realistic vehicle and vehicle-to-grid utilization," J. Power Sources, vol. 195, no. 8, pp. 2385-2392, Apr. 2010.

[37] R. J. Bessa and M. A. Matos, "Economic and technical management of an aggregation agent for electric vehicles: A literature survey," Eur. Trans. Elect. Power, vol. 22, no. 3, pp. 334-350, Apr. 2011.

[38] N. Rotering and M. Ilic, "Optimal charge control of plug-in hybrid electric vehicles in deregulated electricity markets," IEEE Trans. Power Syst., vol. 26, no. 3, pp. 1021-1029, Aug. 2011.

[39] D. O'Neill, E. Akuiyibo, S. Boyd, and A. J. Goldsmith, "Optimizing adaptive modulation in wireless networks via multi-period network utility maximization," in Proc. IEEE ICC, 2010, pp. 1-5.

[40] T. M. Cover and J. A. Thomas, Elements of Information Theory. Hoboken, NJ: Wiley, 1991.

[41] S. P. Boyd and L. Vandenberghe, Convex Optimization. Cambridge, U.K.: Cambridge Univ. Press, 2004.

[42] W. Yu, W. Rhee, S. Boyd, and J. M. Cioffi, "Iterative water-filling for Gaussian vector multiple-access channels," IEEE Trans. Inf. Theory, vol. 50, no. 1, pp. 145-152, Jan. 2004.

[43] R. Jain, D. M. Chiu, and W. R. Hawe, "A quantitative measure of fairness and discrimination for resource allocation in shared computer system," Eastern Res. Lab., Digital Equipment Corp., Hudson, MA, 1984.

[44] MINI, U.S.A., Mini E Specifications, 2011. [Online]. Available: http:// www.miniusa.com/minie-usa/

[45] Mitsubishi Motors, iMiEV Specs., 2011. [Online]. Available: http:// global.ev-life.com/

[46] Tesla Motors, Tesla Roadster Specs., 2012. [Online]. Available: http:// www.teslamotors.com/roadster/specs

[47] N. Raman, G. Chagnon, K. Nechev, A. Romero, and T. Sack, "Saft high power Li-ion automotive battery technology," in Proc. 20th Int. EVS Exp., Long Beach, CA, 2003, vol. 20, p. 12.

[48] Markets and Operational Data: Pricing Data, Load Data and Power Grid Data, NYISO, New York, Mar. 8, 2012. [Online]. Available: http://www. nyiso.com/public/markets_operations/market_data/load_data/index.jsp

[49] A. Dinger, M. Ripley, X. Mosquet, M. Rabl, D. Rizoulis, M. Russo, and G. Sticher, "Batteries for electric cars: Challenges, opportunities, and the outlook to 2020," Boston Consulting Group, Boston, MA, 2010.

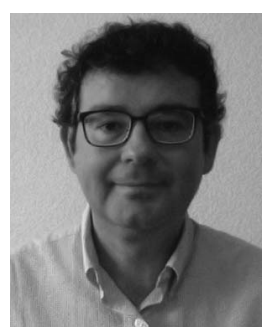

José Joaquín Escudero-Garzás (S'06-M'10) received the Ph.D. degree in electrical engineering from the University Carlos III de Madrid, Madrid, Spain, in 2010.

From 1997 to 2002, he was with Unión Fenosa and Jazztel as a Provisioning Engineer and as Head of the Telecommunications Network Maintenance Department. In 2002, he joined the University Carlos III de Madrid as Assistant Lecturer, where he has taught more than 12 courses related to telecommunication systems and wired/wireless communications, participating in several competitive national and European projects. He was a Guest Researcher with the Communications and Remote Sensing Laboratory, Université Catholique de Louvain, Louvain, Belgium, from March to August 2008. Since October 2010, he has been a Postdoctoral Researcher with the Department of Telecommunications and Systems Engineering, Universitat Autònoma de Barcelona, Barcelona, Spain. His research interests are optimization and game-theory-based techniques applied to smart grid and wireless communication systems. 


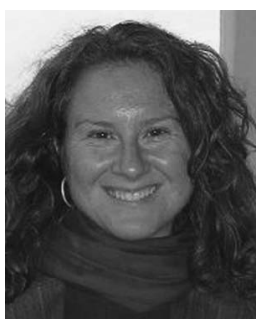

Ana García-Armada (S'96-A'98-M'00-SM'08) received the Ph.D. degree in electrical engineering from the Polytechnic University of Madrid, Madrid, Spain, in February 1998.

She is currently Professor with the Department of Signal Theory and Communications, University Carlos III de Madrid, where she has occupied a variety of management positions. She leads the Communications Research Group and the Laboratory of Communication Systems for Security and Space in the Scientific Park of the same university. She has participated in several national and international research projects related to wireless communications. She is the coauthor of eight book chapters on wireless communications and signal processing. She has authored more than 35 papers in international journals and more than 50 contributions to international conference proceedings. She has contributed to international organizations such as the International Telecommunication Union and European Telecommunications Standards Institute. Her research interests are orthogonal frequencydivision multiplexing and multiple-input-multiple-output techniques and signal processing applied to wireless communications.

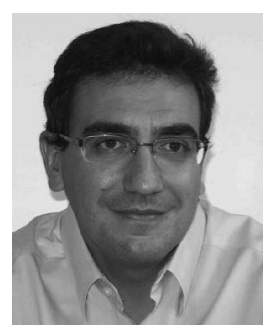

Gonzalo Seco-Granados (S'97-M'02-SM'08) received the Ph.D. degree in telecommunication engineering from the Universitat Politècnica de Catalunya, Barcelona, Spain, in 2000 and the M.B.A. degree from IESE-University of Navarra, Barcelona, in 2002 .

During 2002-2005, he was a Member of Technical Staff with the RF Payload Division, European Space Research and Technology Center, European Space Agency, Noordwijk, The Netherlands, where he was involved in the Galileo Project. He led activities concerning navigation receivers and indoor positioning for the Global Positioning System and Galileo. Since 2006, he has been an Associate Professor with the Department of Telecommunications and Systems Engineering, Universitat Autònoma de Barcelona (UAB), Barcelona. From March 2007 to April 2011, he was the Coordinator of the Telecommunications Engineering degree. Since May 2011, he has been the Vice Director of the UAB Engineering School. In March 2008, he was appointed as Director of one of the six Chairs of Technology and Knowledge Transfer "UAB Research Park-Santander." He has been the principal investigator of more than 12 national and international research projects and often acts as an adviser of the European Commission on topics related to communications and navigation. He has authored 20 journal papers and more than 80 conference contributions. His research interests include signal processing for wireless communications and navigation, location-based communications, optimization, and resource allocation. 